\section{PHARMACEUTICAL COMPOUND REMOVAL DURING MIXED LIQUOR FILTRATION IN MEMBRANE BIOREACTOR OPERATED UNDER LONG SLUDGE AGE}

\author{
Sirilak Prasertkulsak, Chart Chiemchaisri", Wilai Chiemchaisri
}

Department of Environment Engineering, Faculty of Engineering, Kasertsart University, Bangkok 10900, Thailand
Article history

Received

19 September 2017

Received in revised form

30 December 2017

Accepted

1 March 2018

Published online

10 May 2018

*Corresponding author fengccc@ku.ac.th

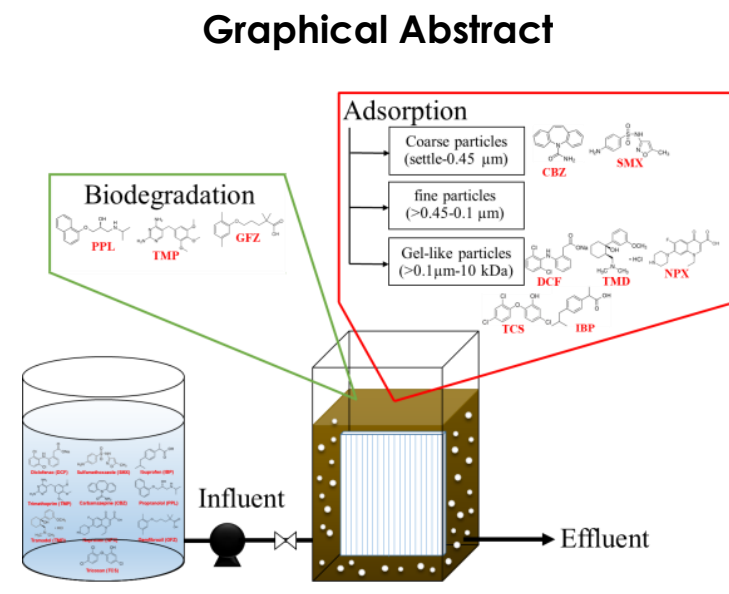

\begin{abstract}
Removals of 10 pharmaceutical compounds by different size particle fractions in the mixed liquor of a membrane bioreactor (MBR) operated under infinite solid retention time (SRT) were investigated. The distribution of pharmaceutical compounds of different particle size fraction in the mixed liquor of MBRs sludge was determined by fractionating the particles into different size fractions by using different separation techniques. Permeate obtained from each membrane filter was analyzed for residual concentration of pharmaceut8cal compounds using LC-MS/MS and HPLC-UV/Vis analyses. High removals (>80\%) of DCF, TMP, NPX, IBP and TCS were observed but CBZ removals were low (<40\%). Adsorption onto coarse particle $(>0.45 \mu \mathrm{m})$ was the major phenomena responsible for the removal of hydrophobic compounds while adsorption onto fine particles and gel-like substances ( $1 \mathrm{kDa}-0.45 \mu \mathrm{m})$ contributed significantly to the removals of hydrophilic and moderate hydrophobic compounds. The Majority of pharmaceutical compounds except CBZ and SMX could be adsorbed onto fine particles and gel-like substances and subsequently rejected during membrane filtration in the MBR. Operation of the MBR at high sludge concentration under long sludge age condition helped enhancing the removals of several pharmaceutical compounds via adsorption onto coarse and fine particles.
\end{abstract}

Keywords: Adsorption, membrane bioreactor, micro-pollutants, particle size, SRT

(C) 2018 Penerbit UTM Press. All rights reserved

\subsection{INTRODUCTION}

Increasing usage and discharge of pharmaceutical compounds into the natural environment has received great attention worldwide. Although pharmaceutical compounds are normally presented at relatively low concentrations in wastewater [1], they can still have a significant adverse impact to human health and living organisms in the ecosystem.

In urban area, pharmaceutical compounds are being discharged from various sources including hospitals, industries, commercial and domestic activities. Hospitals are one of the major sources contributing pharmaceutical compounds into municipal sewerage systems [2] and pre-treatment of its wastewater might be required prior to their discharge into conventional biological treatment processes [3]. Generally, the removals of these compounds in conventional wastewater treatment processes is limited as the majority of them are non or slowly biodegradable and specific microbial activities to improve their removals in the biological process are needed [4]. Development of new 
treatment systems which are effective in removing pharmaceutical compounds will be required in order to minimize their presence in the effluent after treatment and avoid the long-term negative effect from their accumulation in the natural environment.

In recent years, membrane bioreactors (MBRs) have been developed and applied to the treatment of wastewater in order to achieve good effluent quality for reuse purposes. They have a smaller footprint, and produce less sludge when compared to conventional wastewater treatment processes such as the activated sludge (CAS) process. Previous studies have reported that the removal efficiencies of pharmaceutical compounds during MBR treatment were higher and more stable than those in CAS $[5,6]$. This is due to the fact that MBRs can retain sludge in the system at higher concentration thus increasing the liquid-solid interface while promoting better microbial degradation under long sludge age conditions $[7,8]$. Some literature reported that the adsorption and biodegradation of pollutants in MBRs are dependent on operational conditions such as hydraulic retention time (HRT), solid retention time (SRT), biomass concentration, temperature, and $\mathrm{pH}$ of influent [9]. Kimura et al. [6] and Maeng et al. [9] found that the operating condition of the MBR at longer SRT may enhance the removal of pharmaceutical compounds when compared to short SRT. However, the responsible mechanisms resulting in the improvement of those compounds removals in the MBRs are still not well understood. SRT is an important factor affecting the performance of bioreactors, as the SRT can have a significant influence on the biomass properties in an MBR system. A long SRT is considered advantageus because the amount of excess sludge production is reduced and the cost of sludge handling and disposal is reduced. Since higher biomass concentrations results in higher treatment efficiencies, many MBRs are operated with higher SRTs. Nevertheless, microbial communities and activites in the MBRs operated at high SRTs might also affect the removals of pharmaceutical compounds $[10,11]$.

In our recent research, we investigated the removal of pharmaceutical compounds from hospital wastewater in a pilot-scale MBR by operating at a HRT of $3 \mathrm{~h}$ in order to understand fate and removal mechanisms of pharmaceuticals compounds during MBR treatment. It was found that the removal efficiencies of pharmaceutical compounds operating at short HRT were effectively removed. The removal mechanisms for the majority of these compounds was adsorption onto colloidal particles supernatant in the MBR, even though the colloidal particles accounted for only a 0.8-1.0\% fraction and the adsorption capacity of the pharmaceutical compounds depended on MLSS concentration [12]. However, the responsible mechanism for their removal has not been systematically studied or quantified. In this study, the removal efficiencies of pharmaceutical compounds contained in synthetic wastewater in a lab-scale MBR operation by various hydraulic retention time under no sludge wastage conditions were investigated. Special attention has been paid to adsorptive removal of pharmaceutical compounds by different particle size fractions of the mixed liquor in the MBR.

\subsection{METHODOLOGY}

\subsection{Experimental Setup}

Two laboratory-scale MBRs with a working volume of $5.25 \mathrm{~L}$ (Figure 1) were started-up and operated with various MLSS concentration. Hollow-fibre membranes (PVDF Sterapore SADFTM, Mitsubishi Corporation, Japan) with nominal pore size of $0.4 \mu \mathrm{m}$ and total surface area of $0.315 \mathrm{~m}^{2}$ (3 module, $0.105 \mathrm{~m}^{2}$ surface area each) were used for solid-liquid separation. The influent and effluent flow rates were set at $21 \mathrm{~L} / \mathrm{d}$ by operation of the filtration and relaxation modes at 7 min on and 1 min off. The MBRs were operated at different hydraulic retention time (HRT) of $6 \mathrm{~h}\left(M B R_{1}\right)$, and $3 \mathrm{~h}\left(\mathrm{MBR}_{2}\right)$ conditions while the mixed liquor suspended solids (MLSS) concentration was allowed to increase freely during the operation. Aeration was supplied by an air pump at $10 \mathrm{~L} / \mathrm{min}$ (equivalent to specific aeration demand per membrane area of $1.90 \mathrm{~m}^{3} / \mathrm{m}^{2}$.h) to support the biological activities of microorganisms and membrane fouling control was by maintaining the dissolved oxygen level (DO) in the reactor at $5 \mathrm{mg} / \mathrm{L}$ or more. Synthetic wastewater was used to simulate actual hospital wastewater and to maintain a stable operating condition.

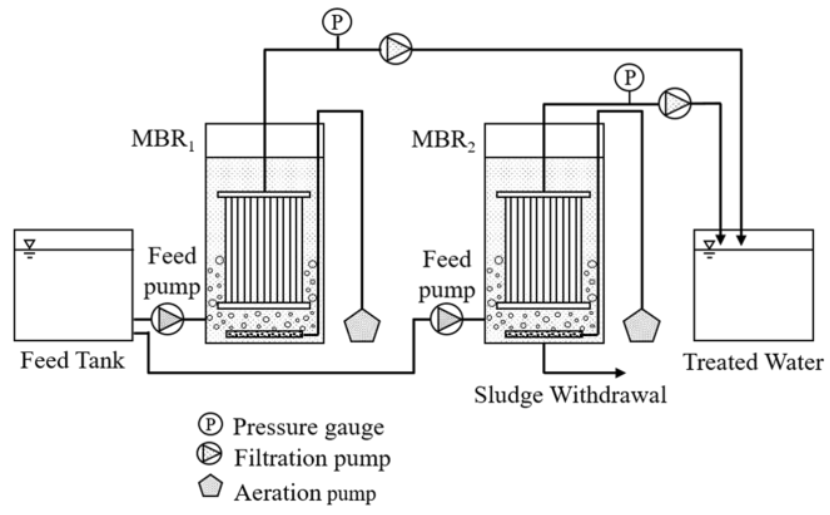

Figure 1 Schematic diagram of laboratory-scale MBR set-up

\subsection{Water Qualities and Pharmaceutical Compound Analyses}

The characteristics of the MBR influent and effluent were analysed according to Standard Methods for the Examination of Water and Wastewater [13]. Biomass concentration in the MBR was regularly monitored in terms of mixed liquor suspended solids (MLSS), mixed liquor volatile suspended solids (MLVSS). The concentration of pharmaceuticals compounds was analysed separately both in solid 
and soluble forms, the analytical methods described in Prasertkulsak et al. [12] were used. Samples were extracted by solid phase extraction by using an Oasis HLB 3 CC cartridge (Waters, Millford, MA, USA). Analytes were separated by using LC-MS/MS (Varian Inc., Palo Alto, CA, USA). High performance liquid chromatography (HPLC, ShimadzU, Japan) with UV detection was used to determine the pharmaceutical compounds in all batch experiments. Calibration generally yielded standard curves with coefficients of determination $\left(R^{2}\right)$ greater than 0.98 within the range of the experimental concentrations used. The analysis was carried out immediately upon the termination of each experiment. Batch experiments were performed to determine combined removals of pharmaceuticals compounds via adsorption and biodegradation mechanisms using MBR sludge.

2.3 Quantification of Adsorbed Pharmaceutical Compounds of Different Particle Size Fraction in Mixed Liquor

The distribution of pharmaceutical compounds of different particle size fraction in the mixed liquors of $M B R_{1}$ and $\mathrm{MBR}_{2}$ sludge was determined by fractionating the particles into different size fractions by using different separation techniques i.e. 1) gravity sedimentation for $30 \mathrm{~min}, 2$ ) centrifugation at 7000 rpm for $10 \mathrm{~min}, 3)$ filtration through different microfiltration membrane filters including GF/C paper, 0.45 and $0.2 \mu \mathrm{m}$ Nylon (Whatman) and $0.1 \mu \mathrm{m}$ PVDF (Sterlitech) membranes, 4) filtration through different ultrafiltration membrane filters (Millipore) including $800 \mathrm{kDa}, 100 \mathrm{kDa}, 10 \mathrm{kDa}$ and $1 \mathrm{kDa}$ (Steritech) molecular weight cut-off (MWCO) in vacuum filter (Supelco Co.,Ltd). After the samples were filtered through each membrane sizing, permeate obtained from each membrane filter was analysed for residual concentration of pharmaceutical compounds. The amount of adsorbed compounds of different particle size fractions was then calculated and they were grouped into different categories, i.e. 1) coarse particles which refer to the particles larger than 0.45 $\mu \mathrm{m}$ (close to nominal membrane pore size in the $M B R$ ), 2) fine particles which refer to the particle size in the range of 0.1-0.45 $\mu \mathrm{m}$ and 3) gel-like substances which refer to the particles and substances smaller than $0.1 \mu \mathrm{m}$ to $1 \mathrm{kDa} \mathrm{MW}$.

\subsection{RESULTS AND DISCUSSION}

\subsection{Treatment Performance of MBR}

The performance of the lab-scale MBR including $\mathrm{pH}$, SS, BOD, COD, $\mathrm{NH}_{3}$, and TKN are summarized in Table 1. The BOD concentration in the effluent of $M B R_{1}$ and $M B R_{2}$ was found to be $0.90 \mathrm{mg} / \mathrm{L}$ and $1.03 \mathrm{mg} / \mathrm{L}$, yielding high BOD removals of $99.53 \%$, and $99.33 \%$ whereas COD removals were $94.49 \%$ and $93.11 \%$ respectively. These results indicate high organic removal efficiencies in the MBRs. Meanwhile, $\mathrm{NH}_{3}$ removal efficiencies in $M B R_{1}$ and $M_{B} R_{2}$ were also higher than $92 \%$ during stable operation which indicates complete nitrification since nitrate was found to be the major nitrogen form in the effluent. Under long SRT condition, autotrophic nitrifiers could proliferate in the reactor without any loss due to its complete retention in the system by membrane filtration. Thus, it could promote the development of nitrifiers, resulting in high $\mathrm{NH}_{3}$ removal. In addition, since the food to microorganisms (F/M) ratio was maintained at a low value under long SRT condition, nitrifying bacteria was subject to less competition from other heterotrophic microorganisms and became the active consumers of ammonia nitrogen.

During $M B R_{1}$ operation, MLSS was increasing from $8 \mathrm{~g} / \mathrm{L}$ to $18 \mathrm{~g} / \mathrm{L}$ without sludge wastage while it was increased from $11 \mathrm{~g} / \mathrm{L}$ to $17 \mathrm{~g} / \mathrm{L}$ in $M \mathrm{MR}_{2}$. During the operation, the MLVSS/MLSS ratio in both MBRs was kept constant at 0.9. As a result, food to microorganisms (F/M) ratio in $M B R_{1}$ was reduced from 0.102 to $0.045 \mathrm{gBOD} / \mathrm{gMLVSS}$.d while it was reduced from 0.145 to $0.094 \mathrm{gBOD} / \mathrm{gMLVSS}$.d in MBR2. Despite an increase in MLSS concentration, the transmembrane pressure inside both MBRs were kept at a relatively low value of $-10 \mathrm{kPa}$, no significant membrane fouling was observed when maintaining a constant permeate flux at $2.8 \mathrm{~L} / \mathrm{m}^{2}$.h and $5.6 \mathrm{~L} / \mathrm{m}^{2} . \mathrm{h}$ respectively. Deng et al. [14] reported that high retention of sludge, colloidal particles, macromolecular matter and microbial products in the MBR could lead to membrane fouling. Li et al. [15] and Lee and Kim [16] reported that an increase in MLSS concentration from 5 to $15 \mathrm{~g} / \mathrm{L}$ could result in a nine-fold increase in membrane fouling. Nevertheless, the low permeate- flux employed in this study coupled with high aeration intensity while maintaining low sludge viscosity in the MBR (5-10 $\mathrm{N} / \mathrm{m}^{2} . \mathrm{s}$ ) did not yield significant formation of a cake layer on the membrane surface in the MBRs.

\subsection{Removal Mechanisms of Pharmaceutical Compounds}

Table 2 shows the average removal efficiencies of the studied pharmaceutical compounds. The removal efficiency of each individual pharmaceutical compounds from the aqueous phase was relatively stable during the operation. 
Table 1 Treatment performance of the MBRs under different MLSS concentrations

\begin{tabular}{|c|c|c|c|c|c|}
\hline \multirow[b]{2}{*}{ Parameter } & \multirow[b]{2}{*}{ Influent } & \multicolumn{2}{|c|}{ MBRI (2.8 LMH) } & \multicolumn{2}{|c|}{$\mathrm{MBR}_{2}$ (5.6 LMH) } \\
\hline & & Effluent* & $\begin{array}{l}\text { Removal } \\
\text { Efficiency (\%) }\end{array}$ & Effluent* & $\begin{array}{l}\text { Removal } \\
\text { Efficiency (\%) }\end{array}$ \\
\hline $\mathrm{pH}$ & $7.49(0.72)$ & $7.18(2.98)$ & & $7.02(2.24)$ & \\
\hline ss (mg/l) & $25.81(20.40)$ & ND & 100 & ND & 100 \\
\hline BOD (mg/l) & 204.67 (64.14) & $0.90(0.87)$ & 99.53 & $0.90(0.50)$ & 99.39 \\
\hline COD (mg/l) & $262.62(10.56)$ & $13.9(10.56)$ & 94.49 & 14.88 (13.58) & 93.11 \\
\hline $\mathrm{NH}_{3}-\mathrm{N}(\mathrm{mg} / \mathrm{l})$ & $22.86(4.04)$ & $0.50(0.45)$ & 97.89 & $1.17(1.08)$ & 92.78 \\
\hline TKN (mg/l) & $30.59(6.27)$ & $1.27(0.92)$ & 96.38 & $1.62(1.76)$ & 94.03 \\
\hline $\mathrm{NO}_{3}-(\mathrm{mg} / \mathrm{l})$ & $0.56(0.91)$ & $18.29(6.57)$ & & $21.36(1.24)$ & \\
\hline
\end{tabular}

ND: Not detected *Average (SD) values

Nevertheless, the removals between compounds varied significantly. In $M \mathrm{MR}_{1}$, removal efficiencies of DCF, TMP, NPX, IBP and TCS showed high removal efficiency (>80\%) followed by TMD, PPL, and GFZ which had moderate removal efficiencies $(60 \%-80 \%)$ whereas the removal efficiencies of SMX $(48.21 \%)$, and CBZ (15.74\%) were found the lowest. In MBR2, TMP, NPX, PPL, and TCS showed higher removal efficiency (>80\%) whereas DCF, SMX, IBP, and GFZ showed moderate removal efficiency (60\%-80\%). CBZ and TMD were found to have a low removal efficiency $(<50 \%)$ during the operation. Comparing $M B R_{1}$ and $M B R_{2}$, the removal efficiencies of DCF and IBP was reduced from $99.26 \%$ to $61.23 \%$ and $95.58 \%$ to $73.48 \%$ respectively when HRT decreased. This could be explained by the removal efficiency of DCF and TCS can be improved by extending their contact time with sludge. A similar tendency was shown in the case of NPX, TCS, and GFZ there was no significant effect of HRT on their removals over the operation period. In a previous study, long term operation of an MBR under prolonged SRT conditions was reported to be associated with some operational problems including inefficient mixing and increased aeration demand for the biological metabolism and membrane cleaning [17].

\subsection{Adsorption and Biodegradation Capacities of} Pharmaceutical Compounds by MBR Sludge

Batch experiments were carried out using mixed liquor obtained from MBR, (when MLSS concentration was at $18 \mathrm{~g} / \mathrm{L}$ ) and $\mathrm{MBR}_{2}$ (at MLSS of $17 \mathrm{~g} / \mathrm{L}$ ) to investigate their capacities to adsorb and biodegrade individual pharmaceutical compounds. The results of the batch experiments using inactivated and active sludge were used to derive the removal efficiencies of pharmaceutical compounds by mixed liquor after $6 \mathrm{~h}$ via adsorption and total (adsorption plus biodegradation) removal. Considering the high removal percentages via adsorption as compared to those of total removal, it was found that adsorption was the main mechanism responsible for the removal of most pharmaceutical compounds in this study. For instance, the removals of DCF, TMP, NPX, PPL, IBP and TCS by MBR, sludge via adsorption were 70.84, 55.40, 54.07, 64.07, 64.94 and $71.90 \%$ which was considered relatively high compared to their total removals of 85.94 and $91.37 \%$ respectively. These two compounds were considered highly removed as compared to the others. Moderately removed compounds were SMX (61.85\%), CBZ (52.98\%), and TMD (65.24\%), whereas GFZ could be removed only at lower percentages (36.92\%). Notable differences in total removal efficiencies of MBR $136.92-91.37 \%$ ) and MBR2 (40.78$90.63 \%$ ) sludge were observed for most compounds except TCS (highest removal) and GFZ (poorest removal). These results suggest that pharmaceutical compounds are generally removed better in a MBR operated under long sludge age conditions via combined adsorption and biodegradation mechanisms even though they did not exhibit evidently during continuous operation of MBR (Table 2). One of the differences between the batch experiment and continuous reactor operation could be the retention of adsorbed compounds onto fine particle and gel-like substances within the reactor during filtration through the fouled membrane in the MBR while they were not accounted for in the batch experiments. It is anticipated that the high biomass concentration promoted a contact opportunity between the pharmaceutical compounds and its biotic surface reaction even though their abiotic adsorption mechanism was not found to be significantly enhanced.

Previous research reported that IBP, NPX, and TCS can be highly biodegraded [17, 18]. However, those compounds were removed mainly through adsorption in this study. This was possibly due the short HRT employed in the experiment ( $3 \mathrm{~h}$ and $6 \mathrm{~h}$ ) therefore the compounds were adsorbed onto particles awaiting further biodegradation. In this study, the removal efficiencies for all studied compounds varied over a wide range depending on the chemical properties of the compounds. The comparison of pharmaceutical compound removal percentages by different mechanisms as determined from batch experiments and observed removal efficiencies during MBR operation is depicted in Figure 2. Adsorption onto coarse particles $(>0.45 \mu \mathrm{m})$ and gel-like substances (1 kDa-0.1 $\mu \mathrm{m})$ were the predominant mechanisms responsible for the removal of most pharmaceutical compounds. 
Table 2 Concentrations and removal of pharmaceutical compounds during MBR operation.

\begin{tabular}{lccccc}
\hline \multirow{2}{*}{ Compounds } & $\begin{array}{c}\text { Influent } \\
(\mu \mathbf{g} / \mathbf{L})\end{array}$ & $\begin{array}{c}\text { Treated water } \\
(\mu \mathrm{g} / \mathbf{L})\end{array}$ & $\begin{array}{c}\text { Removal } \\
\text { efficiency }(\%)\end{array}$ & $\begin{array}{c}\text { Treated water } \\
(\mu \mathrm{g} / \mathbf{L})\end{array}$ & $\begin{array}{c}\text { Removal } \\
\text { efficiency }(\%)\end{array}$ \\
\cline { 3 - 6 } & $403.07-515.04$ & ND-10.59 & 99.26 & $73.85-214.17$ & 61.23 \\
DCF & $382.80-515.47$ & $244.77-266.51$ & 48.21 & $52.67-167.30$ & 78.38 \\
SMX & $336.66-522.17$ & ND-128.18 & 88.13 & $31.09-157.80$ & 80.52 \\
TMP & $432.63-576.67$ & $375.94-476.59$ & 15.74 & $11.02-307.20$ & 41.97 \\
CBZ & $273.55-575.45$ & $28.44-117.77$ & 63.81 & $167.81-372.68$ & 55.27 \\
TMD & $211.89-617.65$ & $7.31-51.67$ & 94.96 & $1.26-35.54$ & 94.36 \\
NPX & $233.73-681.94$ & $8.96-276.78$ & 64.18 & $44.47-147.02$ & 83.12 \\
PPL & $406.32-591.57$ & ND-43.28 & 95.58 & $14.27-181.91$ & 73.48 \\
IBP & $139.39-487.04$ & $4.31-49.81$ & 91.26 & $16.28-65.38$ & 91.88 \\
TCS & $362.20-596.27$ & $56.57-261.70$ & 66.38 & $85.40-246.00$ & 65.39 \\
GFZ & & & & & \\
\hline
\end{tabular}

Between them, the adsorption mechanism onto coarse particles was found to be the main mechanism for the removal of most compounds, excepted SMX, TMP, CBZ and TMD which were found to be removed through adsorption onto fine particles and gel-like substances. The combination of adsorptive removal of all particle size fractions and biodegradation gave a total removal close to that observed in MBR operation for TMP, NPX, and TCS. These results suggest that adsorption onto fine particle and gel-like substances which are much smaller than membrane pore size $(0.4 \mu \mathrm{m})$, and rejection during filtration through fouled membrane played an important role in removing these pharmaceutical compounds in the MBR.

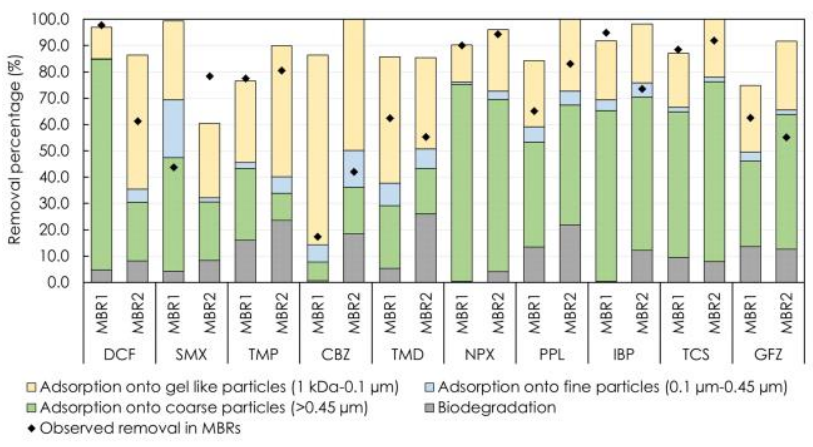

Figure 2 Removals of pharmaceutical compounds during batch experiment and MBR operation

Nevertheless, some compounds were removed in the MBR at a lesser extent. While TMD and PPL were found to be rejected by partial fraction of gel-like substances, CBZ was removed only by the fraction that was adsorbed onto coarse particles. For these latter three compounds, which are classified as moderately hydrophobic and hydrophobic compounds respectively, it is anticipated that the fraction of the compounds was adsorbed onto fine particles and gel-like substances and could not be effectively rejected by the membrane and thus remain in the MBR permeate.

\subsection{CONCLUSION}

Ten pharmaceutical compounds were mainly removed in the MBR through adsorption onto solid particles of different size fractions in the mixed liquor. Moderate to high removal efficiencies were achieved for most compounds during long term MBR operation except for CBZ which was scantily removed (15-42\%). Observed removal efficiencies of NPX, TCS and GFZ were not affected by HRT under long sludge age. The removal efficiencies of pharmaceutical compounds were also improved when the MBR was operated at higher biomass concentration under long sludge age condition.

\section{Acknowledgement}

This research was carried out under AUN/SEED-net collaborative research with industry (CRI) support by Japan International Cooperation Agency (JICA). The authors are also grateful to partial financial support received from Kurita Water and Environment Foundation (KWEF) to this research work.

\section{References}

[1] Luo, Y., Guo, W., Ngo, H. H., Nghiem, L. D., Hai, F. I., Zhang, J., Liang, S., Wang, X. C. 2014. A Review on the Occurrence of Micropollutants in the Aquatic Environment and Their Fate and Removal during Wastewater Treatment. Sci. Total Environ. 473-474: 619-641. DOI: https://doi.org/10.1016/j.scitotenv.2013.12.065.

[2] Verlicchi, P., Galletti, A., Masotti, L. 2010. Management of Hospital Wastewaters: The Case of the Effluent of a Large Hospital Situated in a Small Town. Water Sci Technol. 61: 2507-19.

DOI: http:// 10.2166/wst.2010.138.

[3] Suarez, S., Lema, J. M., Omil, F. 2009. Pre-treatment of Hospital Wastewater by Coagulation-flocculation and Flotation. Bioresour Technol. 100: 2138-2146. DOI: http://doi.org/10.1016/j.biortech.2008.11.015.

[4] Tran, N. H., Urase, T., Ngo, H. H., Hu, J., Ong, S. L. 2013. Insight Into Metabolic and Cometabolic Activities of Autotrophic and Heterotrophic Microorganisms in the Biodegradation of Emerging Trace Organic Contaminants. Bioresour. Technol. 146: 721-731. DOI: https://doi.org/10.1016/j.biortech.2013.07.083. 
[5] Clara, M., Strenna, B., Gans, O., Martinez, E., Kreuzinger, N., Kroiss, H. 2005. Removal of Selected Pharmaceuticals, Fragrances and Endocrine Disrupting Compounds in a Membrane Bioreactor and Conventional Wastewater Treatment Plants. Water Res. 39(19): 4797-4807. DOI: https://doi.org/10.1016/j.watres.2005.09.015.

[6] Kimura, K., Hara, H., Watanabe, Y., 2007. Elimination of Selected Acidic Pharmaceuticals from Municipal Wastewater by an Activated Sludge System and Membrane Bioreactors. Environ. Sci. Technol. 41: 37083714 DOI: http:// 10.1021/es061684z.

[7] Kaya, Y., Ersan, G., Vergili, I., Gonder, Z. B., Yilmaz, G. Dizge, N., Aydiner, C. 2013. The Treatment of Pharmaceutical Wastewater Using in a Submerged Membrane Bioreactor under Different Sludge Retention Times. J. Membr. Sci. 442: 72-82. DOI: https://doi.org/10.1016/j.memsci.2013.03.059.

[8] LI, C., Cabassud, C., Guigui, C. 2015. Evaluation of Membrane Bioreactor on Removal of Pharmaceutical Micropollutants: A Review. Desalin Water Treat. 55(4): 845858. DOI: https://doi.org/10.1080/19443994.2014.926839.

[9] Maeng, S. K., Choi, B. G., Lee, K. T., Song, K. G. 2013. Influences of Solid Retention Time, Nitrification and Microbial Activity on the Attenuation of Pharmaceuticals and Estrogens in Membrane Bioreactors. Water Res. 47: 3151-3162. DOI: https://doi.org/10.1016/j.watres.2013.03.014.

[10] Phan, H. V., Hai, F. I., Zhang, R., Kang, J., Price, W. E., Nghiem, L. D. 2016. Bacterial Community Dynamics in an Anoxic-aerobic Membrane Bioreactor-Impact on Nutrient and Trace Organic Contaminant Removal. Int. Biodeterior. Biodegradation. 109: 61-72. DOI: https://doi.org/10.1016/j.ibiod.2016.01.002.

[11] Zhang, D., Trzcinski, A. P., Kunacheva, C., Stuckey, D. C., Liu, Y., Tan, S. K., 2016. Characterization of Soluble Microbial Products (SMPs) in a Membrane Bioreactor
(MBR) Treating Synthetic Wastewater Containing Pharmaceutical Compounds. Wat Res. 102: 594-606. DOI: https://doi.org/10.1016/j.watres.2016.06.059.

[12] Prasertkulsak, S., Chiemchaisri, C., Chiemchaisri, W. Itonaga, T., Yamamoto, K. 2016. Removals of Pharmaceutical Compounds from Hospital Wastewater in Membrane Bioreactor Operated at Short Hydraulic Retention Time. Chemosphere 150: 624-631.

DOI: https://doi.org/10.1016/j.chemosphere.2016.01.031.

[13] APHA. 2005. Standard Methods for the Examination of Water and Wastewater. 21 st ed. American Public Health Association, Washington DC, USA.

[14] Deng, L. J., Guo, W. S., Ngo, H. H., Zhang, J., Wang, Li, J., S., Xia, Y., Wu. 2016. Biofouling and Control Approaches in Membrane Bioreactors: Review. Bioresour. Technol. 221: 656-665.

DOI: https://doi.org/10.1016/j.biortech.2016.09.105.

[15] Li, J., Yang, F., Liu, Y., Song, H., Li, D., Cheng, F. 2012. Microbial Community and Biomass Characteristics Associated Severe Membrane Fouling during Start-up of a Hybrid Anoxic-oxic Membrane Bioreactor. Bioresour. Technol. 103: 43-47. DOI: https://doi.org/10.1016/j.biortech.2011.09.079.

[16] Lee, S., Kim, M. H. 2013. Fouling Characteristics in Pure Oxygen MBR Process According to MLSS Concentrations and COD Loadings. J. Membr. Sci. 428: 323-330. DOI: https://doi.org/10.1016/j.memsci.2012.11.011.

[17] Avarino, T., Suarez, S., Lema, J. M., Omil, F. 2014. Understanding the Removal Mechanisms o Ppcps and the Influence of Main Technological Parameters in Anaerobic UASB and Aerobic CAS. J. Hazard. Mater. 278: 506-513. DOI: https://doi.org/10.1016/j.jhazmat.2014.06.031.

[18] Joss, A., Zabczynski, S., Göbel, A., Hoffmann, B., Löffler, D., McArdell, C. S., Ternes, T. A., Thomsen, A., Siegrist, H. 2006. Biological Degradation of Pharmaceuticals in Municipal Wastewater Treatment: Proposing a Classification Scheme. Water Res. 40: 1686-1696.

DOI: https://doi.org/10.1016/j.watres.2006.02.014. 